\title{
FULLY MICROFABRICATED, SILICON SPRING BIASED, SHAPE MEMORY ACTUATED MICROVALVE
}

\author{
Geon Hahm, Hal Kahn*, Stephen M. Phillips, Arthur H. Heuer* \\ Department of Electrical Engineering and Computer Science, *Materials Science and Engineering \\ Case Western Reserve University \\ Cleveland, Ohio 44106-7221
}

\begin{abstract}
A microfabricated normally-closed microvalve consisting of a flat silicon spring, a co-sputtered and patterned TitaniumNickel (TiNi) shape memory alloy (SMA) actuator, and an orifice die, is presented. All three components are batch microfabricated using silicon substrates. This microvalve is designed for an actuation mechanism for a pneumatically controlled, biologically inspired six-legged microrobot. We have used a TiNi SMA thin film as an actuator since it is capable of both high strains (3\%) and high forces (work density of $5 \times 10^{7}$ $\mathrm{J} / \mathrm{m}^{3}$ ). Flow rates of up to $0.17 \mathrm{lpm}$ are achieved when the input air pressure is $34.5 \mathrm{kPa}$ (5.0 psi). A C.NC-machined plastic package accommodates the electrical and fluidic interconnects.
\end{abstract}

\section{INTRODUCTION}

There has been extensive research on various types of valves, especially active valves, using microfabrication technology since the late 1980s. Thermopneumatic [1], bimetallic $[2,3]$, shape memory alloy $[4,5]$, electrostatic [6], piezoelectric [7], magnetic [8], and giant magnetostrictive [9] based mechanisms have all been used for actuation. Each actuation method has its own benefits and would be used for specific applications. While thermal inkjet printer nozzles currently have the largest market of all MEMS fluid control devices, the potential is also growing for medical applications. The requirements in pressure tolerance and low leak rates must be fulfilled to compete with conventional valves for many applications [10].

Microvalve design specifications include flow rate, operating pressure, power consumption, actuation speed, leakage, packaging and connectivity to its operating domain. A TiNi SMA actuator has been chosen because its high strains and actuation forces enable high fluid flow rates and high working pressures, respectively.

TiNi SMA exhibits reversible transformation between two characteristic phases: relatively stiff austenite at high temperatures, and relatively ductile martensite at low

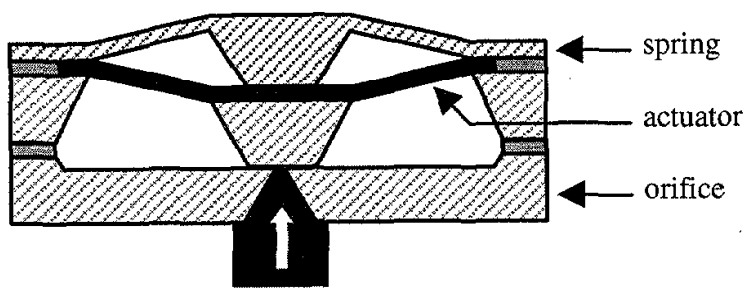

a) temperatures. Both forward and reverse transformations occur above room temperature. Since the transformations occur over a range of temperatures, proportional flow control can be achieved by precise temperature control. The temperature of the SMA actuator can be controlled by joule heating, using an applied current, and forces are generated by the phase transformation.

The successful use of TiNi thin films in MEMS applications has been hindered in previous efforts. One of the most serious problems is the reliable batch fabrication of TiNi thin films with reproducible transformation temperatures and transformation strains. The transformation temperatures and strains are very sensitive to compositional variation. Since the Ti and $\mathrm{Ni}$ constituents in alloy sputtering targets have different sputtering yields during deposition, a co-sputtering procedure has been developed which uses an alloy TiNi target and an elemental Ti target to reliably achieve stoichiometric SMA films [11].

Packaging and assembly of MEMS devices are important considerations which should be improved for product completeness and are application specific [12]. For our microvalve, a package has been developed, which enables easy, reliable assembly and repeatable testing of the fluidic device components. A package for arrays of microvalves is also being designed.

\section{OPERATION OF MICROVALVE}

The microvalve is composed of three components - a flat silicon spring, a patterned TiNi SMA actuator, and an orifice die. They are assembled on top of each other (Figure 1). The valve is normally closed; the fluid flow is proportional to the current applied. The patterned TiNi actuator and silicon spring allow "flow-through" operation. When the fluid direction is reversed, this leads to pressure balancing in the valve which enables much higher input pressures to be modulated.

The spring provides an initial closing force against the orifice making the valve normally closed when the SMA actuator is in its low temperature martensite phase (Figure 1a). When the actuator is heated, it transforms to austenite, forcing the spring upward, opening the valve (Figure 1b). The orifice die

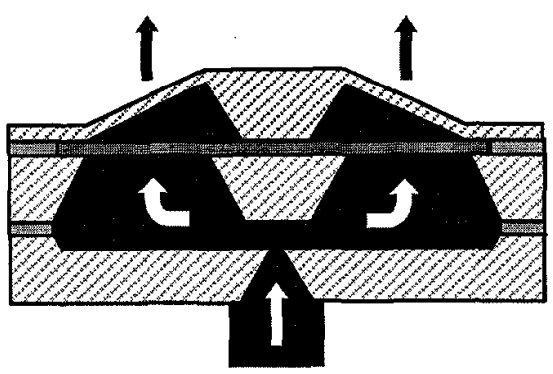

b)

Figure 1. Cross-section of a microvalve, a) closed position, b) open position 


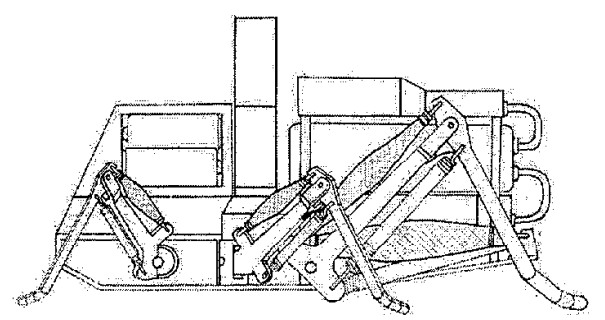

Figure 2. Conceptual design of the microrobot

simply contains a square inlet.

Assembled microvalves will be integrated as an array with pneumatic systems to control actuators in legs of a microrobot. Figure 2 shows the conceptual design of the microrobot.

\section{DESIGN}

A microvalve using an SMA diaphragm actuator has previously been developed in our lab [13]. Its shortcomings included non-uniform temperature across the diaphragm, slow transformation times, and large power consumption. To address these in the current valve design, the TiNi film is patterned into a thin strip, as shown in Figure 3. Two types of finite element analysis have been performed to optimize the design - coupled thermal-electrical analysis and stress-displacement analysis [14]. The reduction of thermal mass greatly reduces the response time and lowers the power consumption.

Component dimensions are intimately related to the mechanical characteristics of the TiNi film and the fluidic device specifications. Specifically, the orifice size is determined by the desired flow rate and the stroke of the boss. The stroke is determined by the dimensions of the patterned TiNi SMA actuator whose design also depends on the force required to modulate the fluid, which depends on the pressure. The spring design is determined by the recovery force of the actuator. Since the spacings between each component are also important factors determining the performance of the valve, accurate control of the thickness of the spacing or bonding material during assembly must be accomplished.

\section{FABRICATION}

One of the most important considerations in fabricating MEMS devices containing $\mathrm{TiNi}$ is process compatibility,

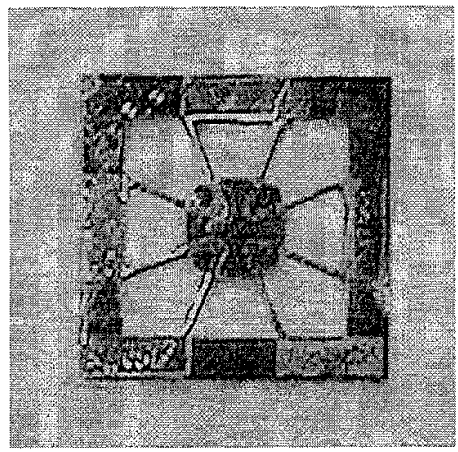

Figure 3. Patterned TiNi SMA actuator, $7.5 \mathrm{~mm} \times 7.5 \mathrm{~mm}$

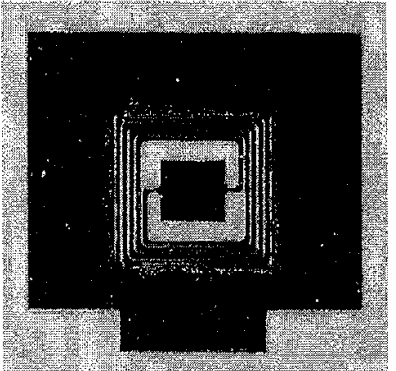

a)

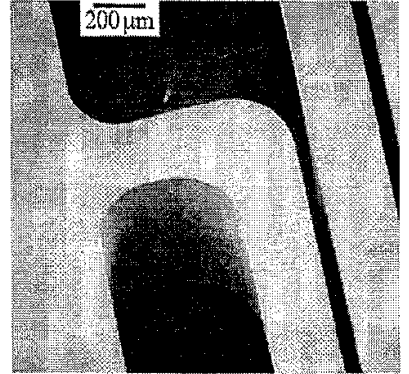

b)
Figure 4. a) Plan view of the bias silicon spring, $7.5 \mathrm{~mm} \times 7.5$ $\mathrm{mm}$; the bottom corners are etched for electrical connection to the actuator, b) SEM of thick silicon spring fabricated using a DRIE etcher

especially with regards to temperature. Since TiNi oxidizes easily when it is heated above $\sim 300^{\circ} \mathrm{C}$ in air, process flows are constrained.

The actuators are fabricated by the following sequence. First, a thin $(25 \mu \mathrm{m})$ silicon diaphragm with a central boss is created by tetramethylammonium hydroxide (TMAH) etching. Convex corner compensation is applied to generate the square boss shape in a limited area. Next, a $2-\mu \mathrm{m}$ TiNi thin film is cosputtered on the silicon diaphragm. Then, the TiNi is patterned into a thin line with standard photolithography and wet etching. The silicon diaphragm is removed in an $\mathrm{SF}_{6}$ plasma to release the patterned TiNi film which is attached to the central boss (Figure 3).

The TiNi thin film SMA's are co-sputtered using a TiNi alloy target and an elemental $\mathrm{Ti}$ target with two independentlycontrolled DC magnetron guns. During deposition, the chamber is evacuated and back-filled with argon gas to $3.5 \mathrm{mTorr}$. The wafer is rotated and heated to $230^{\circ} \mathrm{C}$, and a deposition rate of $\sim 0.25 \mathrm{~nm} / \mathrm{sec}$ is used. After deposition, the film is annealed in situ at $400{ }^{\circ} \mathrm{C}$ for 15 minutes after evacuating the Ar gas from the deposition chamber. Stoichiometric SMA films are routinely achieved.

$400-\mu \mathrm{m}$ thick silicon springs with $200-\mu \mathrm{m}$ wide arms are bulk micromachined using deep-reactive-ion-etching (DRIE) with a $10 \mu \mathrm{m}$-thick photoresist layer as a mask (Figure 4). The $480 \mu \mathrm{m} \times 480 \mu \mathrm{m}$ orifices are bulk micromachined using TMAH. The etch rate is $\sim 48 \mu \mathrm{m} /$ hour at $90^{\circ} \mathrm{C}$.

\section{PACKAGING AND ASSEMBLY}

Two types of packages have been developed. One is for a $\mathrm{Au} / \mathrm{Si}$ eutectic bonded stand-alone device (Figure 5) and the other is for testing device components that have been assembled but not permanently bonded (Figure 6). Computer aided machining is used to cut the packages directly from CAD drawings using acrylic as the structural material. Both designs use two flexible interconnect contacts (gold plated $2.5 \mathrm{~mm}$ long bellows contact springs) to supply the current to heat the SMA actuator, without any direct bonding to the TiNi film surface. The absence of rigid bonds allows for slight misalignment in assembly, and easy re-use of the package.

For the component testing package (Figure 6), the three components of the valve are stacked in the trench machined into the lower half of the package, and the top cover is screwed on tightly. An o-ring (outer diameter of $2.4 \mathrm{~mm}$ ) provides sealing between the orifice and package at the inlet port, and a push-in 


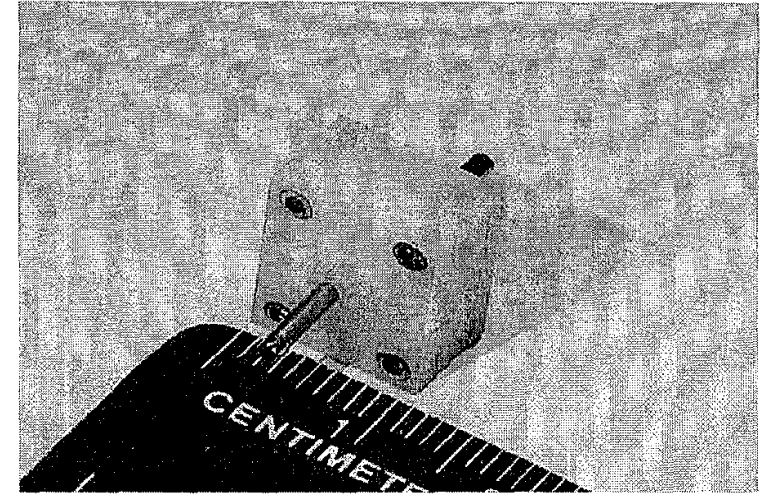

Figure 5. Valve with stand-alone package

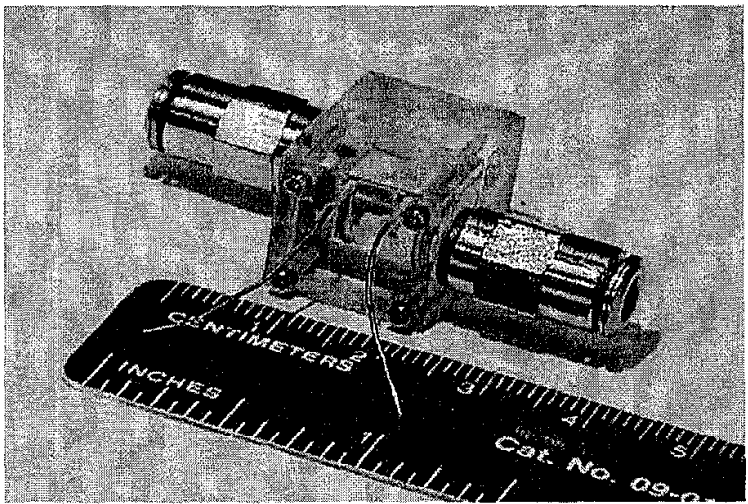

Figure 6. Valve with test package

fitting system (tube diameter $5 / 32^{\prime \prime}$ ) is adapted in the test fixture package for easy pneumatic connections. This packaging scheme allows reliable and repeatable testing of the device components. The stand-alone package (Figure 5) uses thin stainless steel tubing (1/32" diameter) for fluidic connections.

The dimensions of an assembled valve without packaging are $7.5 \mathrm{~mm} \times 7.5 \mathrm{~mm} \times 2 \mathrm{~mm}$. Those with packaging are $11 \mathrm{~mm}$ $\times 13 \mathrm{~mm} \times 7.5 \mathrm{~mm}$ for stand-alone, and $16 \mathrm{~mm} \times 16 \mathrm{~mm} \times 20$ $\mathrm{mm}$ for component testing, without fittings.

\section{TESTING AND RESULTS}

The silicon spring force-deflection behavior was measured by a precision balance and a transfer stage with 1 micron

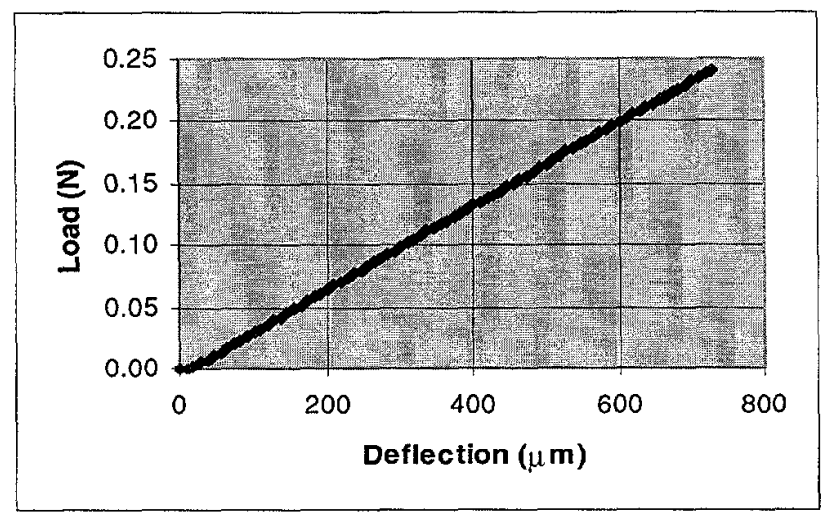

Figure 7. Spring load-deflection characteristic

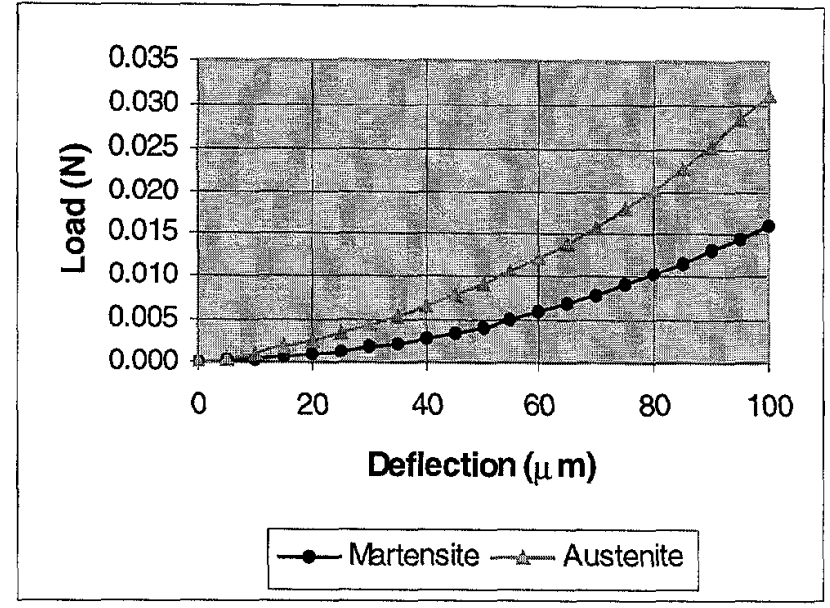

Figure 8. Actuator load-deflection characteristic

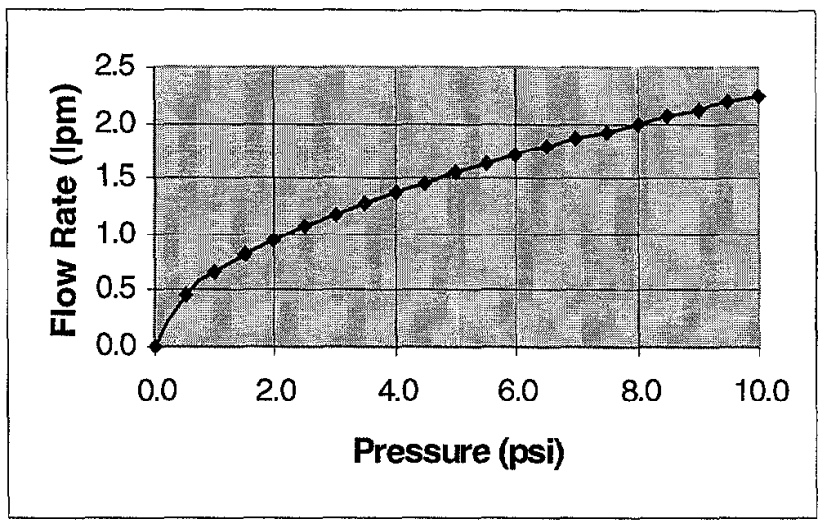

Figure 9. Flow characteristics of an orifice $(480 \mu \mathrm{m} \times 480 \mu \mathrm{m})$

resolution. It was linear to greater than $730 \mu \mathrm{m}$ with a spring constant of $330 \mathrm{~N} / \mathrm{m}$ (Figure 7).

The load-deflection characteristics of a patterned actuator were also acquired (Figure 8). From this data, both recovery force (at a given deflection) and recovery deflection (at a given load) can be determined.

A non-contact, fiber optic, displacement sensor $(880-\mathrm{nm}$ light source) was used to measure displacement and time response during the heating cycle of an SMA actuator attached to a silicon spring. The full deflection range of the combination of a spring and an actuator with a $400-\mu \mathrm{m}$ thick spacer is $\sim 75$ $\mu \mathrm{m}$. Time response was measured with a fully assembled device without fluid by applying a $1-\mathrm{Hz}$ square wave signal. The opening time was $50 \mathrm{msec}$ and the closing time was $18 \mathrm{msec}$. The orifice was also tested, and Figure 9 shows air flow rates through the orifice versus inlet pressure.

Based on dimensions and measurements from all three elements, proper spacer thickness was chosen. The components were assembled and microvalves were investigated for gas (air) flow modulation capabilities with the test setup in Figure 10. Flow rates of up to $0.17 \mathrm{lpm}$ were measured when the input air pressure was $34.5 \mathrm{kPa}$ (Figure 11) and the leakage was 0.005 $1 \mathrm{pm}$. The leakage was most likely due to the surface roughness of the underside of the boss and the top of the orifice, and possible misalignment between the boss and the orifice. It could be reduced by microfabricating a valve seat structure, depositing a flexible thin film at the valve seat, or making series of circular grooves around the inlet port [7]. 


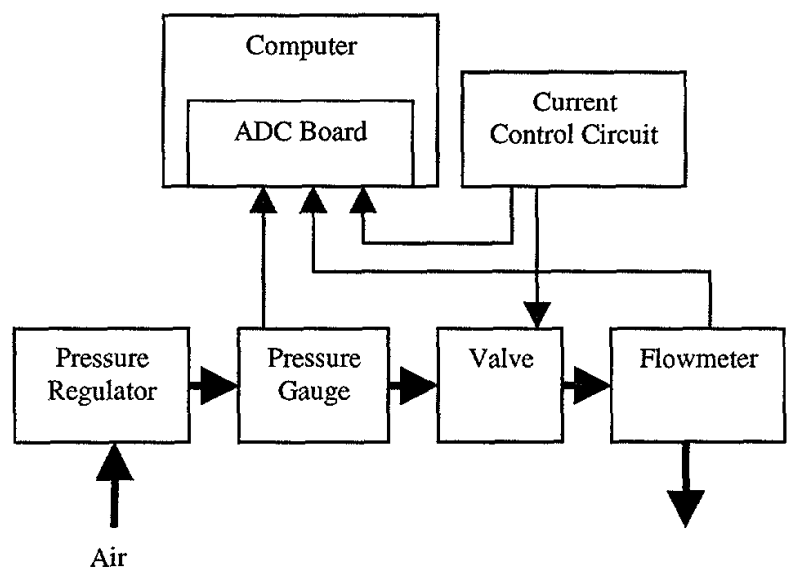

Figure 10. Test setup

\section{CONCLUSION}

A normally-closed TiNi SMA actuated microvalve for gas flow control has been fabricated and successfully tested. It consists of a silicon spring, a patterned TiNi SMA actuator, and an orifice layer. All components are microfabricated from silicon wafers and are compatible with batch processing. Two types of packages have been developed using computer aided machining. This enables easy assembly and repeatable testing. The valve is tested for gas (air) flow modulation. Flow rates of up to $0.17 \mathrm{lpm}$ are demonstrated when the input air pressure is $34.5 \mathrm{kPa}$.

\section{FUTURE WORK}

To optimize device performance, two enhancements are necessary - a reduction in the leakage flow and more reliable packaging. A new package will be developed for a matrix of valves, since one microrobot requires 32 valves. Au/Si eutectic wafer bonding will be further refined for batch assembly.

Polyimide thermal insulation layers are being pursued to reduce the power consumption and response time, and for fluid isolation when using liquid media. In addition, driving the actuator with pulses of current are being investigated to further reduce the power consumption. Efforts to reduce the leakage are underway.

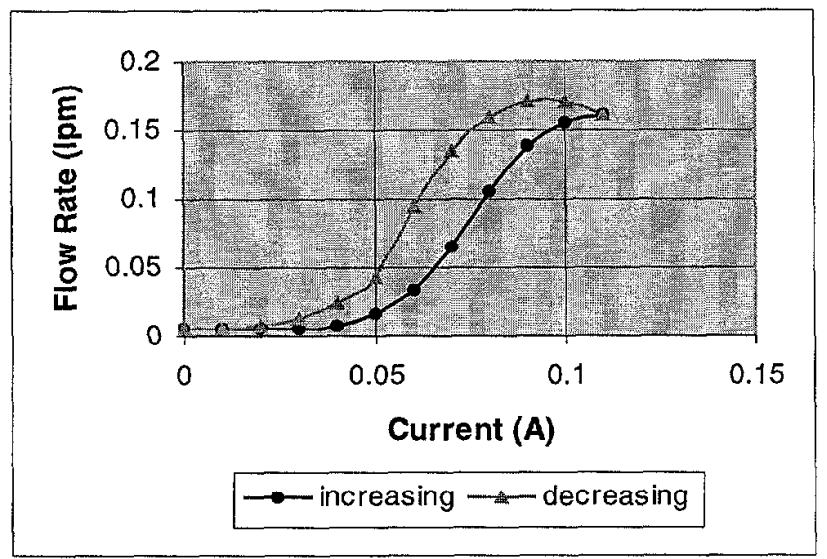

Figure 11. Flow rate vs. current (air, 5 psi)

\section{ACKNOWLEDGMENTS}

This work was supported in part by the DARPA Distributed Robotics Program under contract D $\Lambda$ RP $\Lambda$ /ETO DAAN02-98-C-4027. We also acknowledge the early contributions to the work by Dr. M. Huff and W. Benard [13].

\section{REFERENCES}

1. M. J. Zdeblick, R. Anderson, J. Jankowski, B. KlineSchoder, L. Christel, R. Miles, W. Weber, "Thermopneumatically actuated microvalves and integrated electro-fluidic circuits," Solid-State Sensor and Actuator Workshop, 1994, pp. 251-255.

2. P. W. Barth, C. C. Beatty, L. A. Field, J. W. Baker, G. B. Gordon, "A robust normally-closed silicon microvalve," SolidState Sensor and Actuator Workshop, 1994, pp. 248-250.

3. H. Jerman, "Electrically-activated, micromachined diaphragm valves," J. Micromech. Microeng. 4, 1994, pp. 210216.

4. C. A. Ray, C. L. Sloan, A. D. Johnson, J. D. Busch, B. R. Petty, "A silicon-based shape memory alloy microvalve," Mat. Res. Soc. Symp. Proc. Vol. 276, 1992, pp. 161-166.

5. W. L. Benard, H. Kahn, A. H. Heuer, M. A. Huff, "A Titanium-Nickel shape-memory alloy actuated micropump," Int. Conf. Solid-State Sensors and Actuators, 1997, pp. 361-364.

6. M. A. Huff, M. S. Mettner, T. A. Lober, M. A. Schmidt, "Fabrication, packaging, and testing of a wafer-bonded microvalve," Solid-State Sensor and Actuator Workshop, 1992 pp. 194-197.

7. I. Chakraborty, W. C. Tang, D. P. Bame, T. K. Tang, "MEMS micro-valve for space applications," Transducers '99, 1999, pp. 1820-1823.

8. R. L. Smith, R. W. Bower, S. D. Collins, "The design and fabrication of a magnetically actuated micromachined flow valve," Sensors and Actuators A, 24, 1990, pp. 47-53.

9. E. Quandt and K. Seemann, Fabrication of giant magnetostrictive thin film actuators, Proc. IEEE MEMS 1995 , 1995, pp. 273-277.

10. MEMS 1999 Emerging Applications and Markets, 1999. System Planning Corporation,

11. C.-L. Shih, Deposition and characterization of TiNi shape memory alloy thin film for MEMS applications, MS thesis, Case Western Reserve University, Department of Materials Science and Engineering, 1999.

12. Microelectromechanical Systems; Advanced Materials and Fabrication Methods, National Materials Advisory Board, National Academy Press, 1997.

13. H. Kahn, W. L. Benard, M. A. Huff, A. H. Heuer, "Titanium-nickel shape memory thin film actuators for micromachined valves," Mat. Res. Soc. Symp. Proc., vol. 444, 1997, pp. 227-232.

14. A. G. Parr Jr., Design and characterization of a patterned actuator and the design and development of a smart controller for a microfluidic valve, MS thesis, Case Western Reserve University, Department of Electrical Engineering and Applied Physics, 1998. 